\title{
Influence of Magnetic-Field Gradients on the Pearlitic Transformation in Steels
}

\author{
Michio Shimotomai* \\ Graduate School of Science and Technology, Chiba University, Chiba 263-8522, Japan
}

Carbon steels of $1 \mathrm{wt} \% \mathrm{C}$ were subjected to the pearlitic transformation in a helium-free superconducting magnet in search for some influence of the magnetic field gradient on the transformation. It was found that steels containing $\mathrm{Mn}$ and/or Cr got hardened proportional to the field gradient present during the transformation at $560^{\circ} \mathrm{C}$. The hardness increase amounted to $8 \%$ at the field gradient of $50 \mathrm{~T} / \mathrm{m}$, the magnitude depending on the steel composition. It was confirmed that the hardening was irrelevant to the sign of the gradient and absent for homogeneous magnetic fields. This kind of hardening was not observed for a binary Fe-C alloy. The hardened specimens exhibited age hardening by annealing at $150 \sim 200^{\circ} \mathrm{C}$. TEM observations and internal friction measurements suggested that supersaturated carbon atoms were introduced into the ferrite layers of the pearlite phase under the field gradient. Such extra carbon atoms should have combined with $\mathrm{Mn}$ and/or Cr atoms during the quenching to impurity complexes responsible for the solution and age hardenings. Plausible arguments are made on the action of magnetic field gradients for the introduction of supersaturated carbon atoms in the pearlitic ferrite.

(Received July 18, 2003; Accepted November 25, 2003)

Keywords: carbon steel, pearlitic transformation, pearlite, magnetic field, magnetic field gradient, hardness, age hardening, transmission microscopy, internal friction, carbide

\section{Introduction}

Influence of magnetic fields on the phase transformation in steels has been a subject of much interest, and two effects have been established. The first one is of thermodynamic origin. If two phases differing in saturation magnetization by an amount $\Delta J$ are placed in a magnetic field $H$ the potential energy of the ferromagnetic phase is lowered by $H \Delta J .{ }^{1)}$ This prediction has become apparent through several studies on athermal martensitic transformation, and a magnetic field is able to cause a rise in the $M_{\mathrm{s}}$ temperature by approximately $3^{\circ} \mathrm{C}$ per magnetic field in the unit of $\mathrm{T}$ (Tesla). ${ }^{2-4)}$ It is also confirmed that the kinetics of a diffusion-controlled transformation such as the ferrite transformation in $\mathrm{Fe}-\mathrm{C}$ steels is influenced by magnetic fields by the same mechanism. ${ }^{5)}$

The other effect of applying external magnetic fields to transforming steels is the formation of aligned microstructures. The first observation of aligned microstructures in steels was made on Fe-C alloys undergoing ferrite to austenite transformation in a magnetic field of $8 \mathrm{~T}$. ${ }^{6,7)}$ The microstructures are chains or columns of the austenite phase developed along the magnetic field in the matrix phase. The explanation was that the alignment was due to anisotropic dipolar interactions between pairs of the paramagnetic austenite grains, regarded as magnetic holes, in the matrix of ferromagnetic ferrite phase. Recently, the formation of aligned two-phase microstructures has been established for steels and $\mathrm{Fe}-\mathrm{C}$ alloys transforming from austenite to ferrite. ${ }^{8)}$ These two effects have been found with homogeneously applied magnetic fields.

Present paper is concerned with a newly found effect of magnetic fields on a phase transformation in carbon steels. A remarkable feature of the effect is that it manifests itself only under magnetic field gradients in carbon steels transforming from austenite to pearlite. Preliminary results on this effect

*Corresponding address: 3-17, 4-1303, Mihama-ku, Chiba 261-0011,

Japan. E-mail: m-shimotomai@msa.biglobe.ne.jp were already reported from the viewpoint of the strengthening of steels. ${ }^{9)}$

\section{Experimental}

Steel ingots of almost eutectoid composition with varying contents of $\mathrm{Mn}$ and $\mathrm{Cr}$ were prepared by vacuum induction melting. Their chemical compositions are listed in Table 1. Here, Steel A has the composition similar to that of SK4 known as a tool steel, since the effect of field gradients was discovered on this steel for the first time. ${ }^{9)}$ The compositions of the other steels in the table were chosen so as to make clear the individual role of alloying elements in Steel A. In the table the elements below 0.01 mass $\%$ were due to impurities of starting materials. Thick plates cut from the ingots were hot-rolled, followed by cold rolling to thin sheets. Specimens of rectangular shape $\left(70 \times 6 \times 1 \mathrm{~mm}^{3}\right)$ were prepared from the thin sheets and subjected to homogenization annealing at $900^{\circ} \mathrm{C}$ for $1.8 \mathrm{ks}$. A helium-free $12 \mathrm{~T}$ superconducting magnet with a vertically penetrating bore of $102 \mathrm{~mm}$ in diameter was used for the present experiments. The experimental setup is found elsewhere. ${ }^{9)}$ A couple of small furnaces were installed in the bore, upper one for austenization of a specimen and lower one for the subsequent pearlitic transformation. The upper furnace had a through bore and

Table 1 Chemical compositions of steels specimens (mass\%) and the fractional increase of hardening in specimens induced by the field gradient of $50 \mathrm{~T} / \mathrm{m}$.

\begin{tabular}{lccccccc}
\hline Steel & $\mathrm{C}$ & $\mathrm{Si}$ & $\mathrm{Mn}$ & $\mathrm{P}$ & $\mathrm{S}$ & $\begin{array}{c}\mathrm{Cr} \\
(\mathrm{mass} \%)\end{array}$ & $\begin{array}{c}\text { Hardening } \\
(\%)\end{array}$ \\
\hline Steel A & 0.96 & 0.20 & 0.40 & 0.009 & 0.004 & 0.19 & $6.7 \pm 0.7$ \\
Steel B & 0.99 & 0.01 & 1.05 & 0.001 & 0.004 & - & $7.9 \pm 0.6$ \\
Steel C & 0.98 & 0.01 & 0.40 & 0.001 & 0.004 & - & $2.1 \pm 0.6$ \\
Steel D & 1.00 & 0.01 & 0.01 & 0.001 & 0.003 & 0.42 & $6.5 \pm 0.6$ \\
Steel E & 0.97 & 0.01 & 0.01 & 0.001 & 0.005 & 0.18 & $2.7 \pm 0.6$ \\
Steel F & 1.02 & 0.01 & 0.01 & 0.001 & 0.001 & - & $0.5 \pm 0.5$ \\
\hline
\end{tabular}




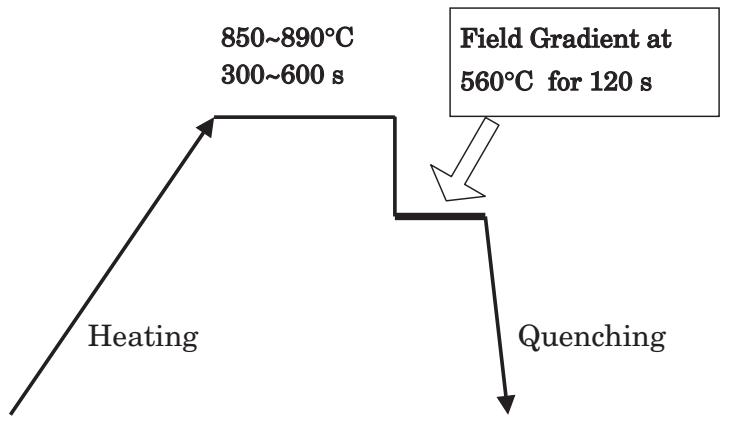

Fig. 1 Typical heat pattern for the specimens.

was set at a position with the magnetic field less than $2 \mathrm{~T}$. The role of the lower furnace was to hold a molten $\mathrm{Pb}$ bath in which the pearlitic transformation of a specimen was to take place. The bath might be located at either of two positions where the field gradient along the bore the magnet is maximum. Conventionally the upper positions were adopted for experiments. The space around the two furnaces and in-between was filled with flowing Ar gas.

A typical experimental procedure was as follows. The field gradient and the temperatures of the furnaces were initially set to constant values. Then a specimen fixed to an edge of a long thin pipe made of SUS 304 was inserted into the upper furnace from top. When the full austenization of the specimen had been completed, it was transferred downward into the molten $\mathrm{Pb}$ bath, so that the center of the specimen coincided with the position of the gradient maximum. After a short period of time for pearlitic transformation, typically $120 \mathrm{~s}$, it was swiftly withdrawn upward above the magnet and rapidly cooled in water. A typical heat pattern for the specimens is shown in Fig. 1. All the specimens subjected to this treatment were confirmed to have the typical pearlite structure by optical microscopy. The field gradient at the center of a specimen was varied between $20 \mathrm{~T} / \mathrm{m}$ with the background magnetic field of $2.5 \mathrm{~T}$ and $64 \mathrm{~T} / \mathrm{m}$ with $7.5 \mathrm{~T}$. It is added that the heat treatment shown above, if carried out without any applied fields, is technologically known as "patenting". The specimens treated in the experimental setup were examined by Vickers hardness, X-ray diffraction (XRD), transmission electron microscopy (TEM, EDX) and internal friction.

\section{Results and Discussion}

\subsection{Effect of magnetic field gradients on hardness}

Initially, specimens of all kinds were subjected to pearlitic transformation with the heat pattern shown in Fig. 1 with and without the field gradient of $50 \mathrm{~T} / \mathrm{m}$. It turned out that most of the steels exhibited an increase of Vickers hardness in the presence of the field gradient. Fractional increase of the hardening is listed in the last column of Table 1. The hardening is most remarkable for Steel B. It is noted the hardening proceeds progressively with Mn content for Steels $\mathrm{C}$ and $\mathrm{B}$ and, with $\mathrm{Cr}$ content for Steels $\mathrm{E}$ and D. It is important to note in Table 1 that the Steel F, a simple Fe-C alloy, shows a negligibly small hardening. If a modification of the spacing of a transformation pearlite by the magnetic field gradient should take place, the corresponding change

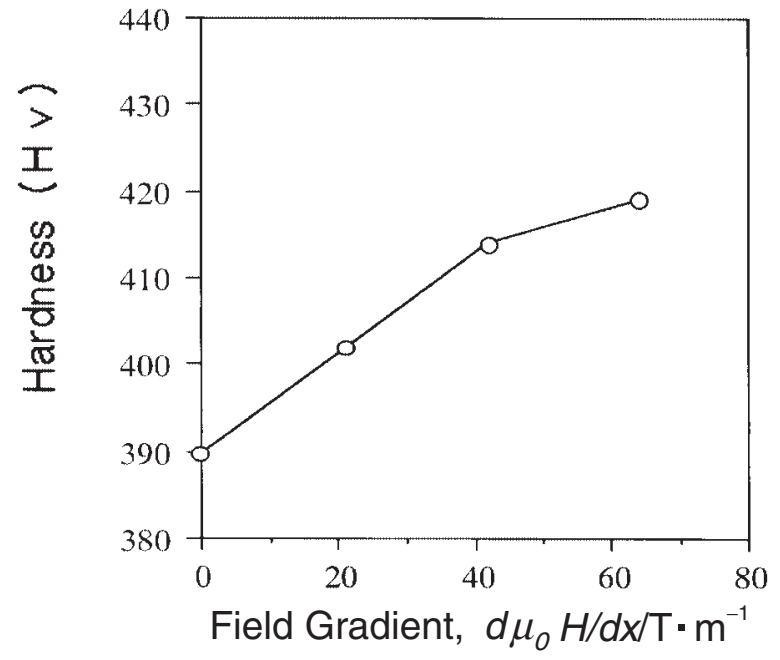

Fig. 2 Relation of hardness of Steel D with field gradient.

would be common to all the specimens and should influence the hardness. However, the hardness of the Fe-C alloy was not altered by the field gradient. This implies that a modification of the spacing of a transformation pearlite by the magnetic field gradient, if any, is not a main cause of the hardening for Steels $\mathrm{A} \sim \mathrm{E}$. By the way, an influence of a body force due to the field gradient, exerted on the ferromagnetic pearlitic ferrite, is briefly commented here. One might presume that such force should be accumulated along a specimen length as a mechanical stress. However, the hardness increase was found to be independent of the position along the specimen. Thus, such magnetic force is not the origin the hardening reported above.

To confirm the hardening with the field gradient, specimens made of Steel D were studied under various field gradients. The results are shown in Fig. 2. It is clear that the specimens do harden with the field gradient. The relation is almost linear up to $40 \mathrm{~T} / \mathrm{m}$. Experiments were also carried out with the $\mathrm{Pb}$ bath located at the lower position of the gradient maximum in the magnet bore. They yielded approximately the same hardening. Thus, the sign of field gradient has made no difference. To the contrary, experiments under a homogeneous magnetic field of $7.5 \mathrm{~T}$ or $12 \mathrm{~T}$ with the $\mathrm{Pb}$ bath at the center of the magnet did not show any hardening compared to a zero field experiment within the experimental error $( \pm 5)$ of the hardness test.

Influence of the holding time in the $\mathrm{Pb}$ bath was studied with a specimen made of steel $\mathrm{A}$. The field gradient was $50 \mathrm{~T} / \mathrm{m}$. For comparison a reference experiment was also done with no applied fields. The results are shown in Fig. 3. It is remarkable that the hardening is dependent on the holding time and that it starts to diminish for duration longer than $120 \mathrm{~s}$. This behavior suggests that a meta-stable phase might be involved in the hardening. However, XRD patterns taken for specimens of Steels B and D subjected to the field gradient showed diffraction patterns no different from those of pearlite structures. Therefore, a conjecture of the formation of a transient phase between austenite and pearlite phases was ruled out. The second possibility was the introduction of highly mobile atoms during the pearlitic transformation under the field gradient. If such extra atoms 


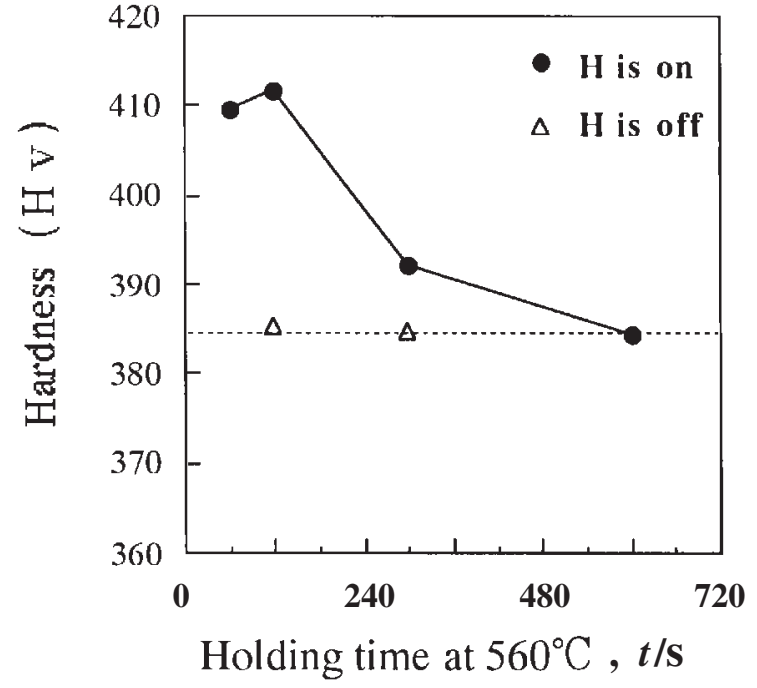

Fig. 3 Influence of the holding time in the $\mathrm{Pb}$ bath on the hardness of specimen made of steel A. The field gradient was $50 \mathrm{~T} / \mathrm{m}$.

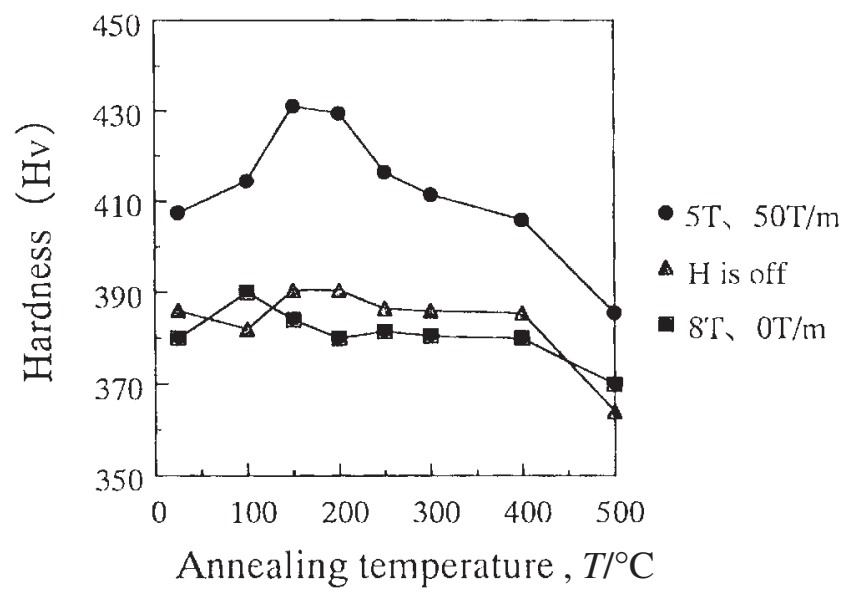

Fig. 4 Variation of hardness with isochronal annealing for specimens made of Steel A.

were to be present, one might attribute the hardening of the specimens to a kind of solution hardening.

\subsection{Aging behavior and TEM observations}

To examine the second possibility mentioned above, isochronal annealing experiments were carried out for specimens made of Steels A, B and D subjected to the treatment shown in Fig. 1. Figure 4 shows changes of Vickers hardness with $1.8 \mathrm{ks}$ isochronal annealing for specimens made of Steel A. The specimen treated under a field gradient has a clear peak around $150 \sim 200^{\circ} \mathrm{C}$, while specimens subjected to a homogeneous field of $8 \mathrm{~T}$ or zero field show almost flat curves. Results for Steels B and D also exhibited similar peaks at the same temperature range. This kind of peak in hardness appearing with the annealing of quenched metals and alloys is known as age hardening, and is usually attributed to small coherent precipitates which grow to incoherent precipitates with associated loss of the hardening upon further annealing. It is added that interstitial carbon atoms and their complexes with impurities are known to be very mobile around $150^{\circ} \mathrm{C}$ in steels. (a)

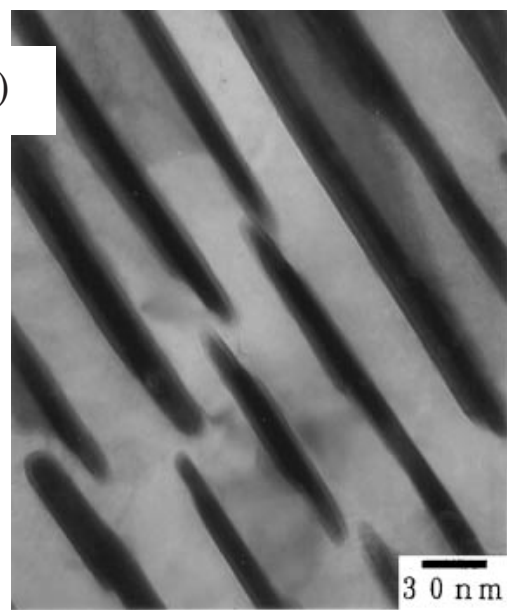

(b)

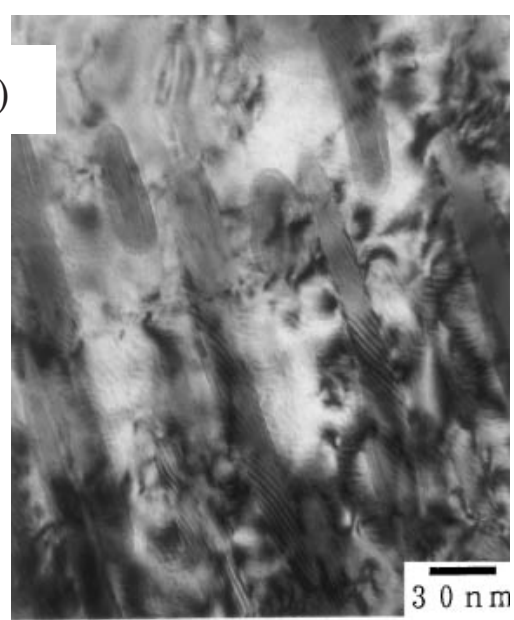

(c)

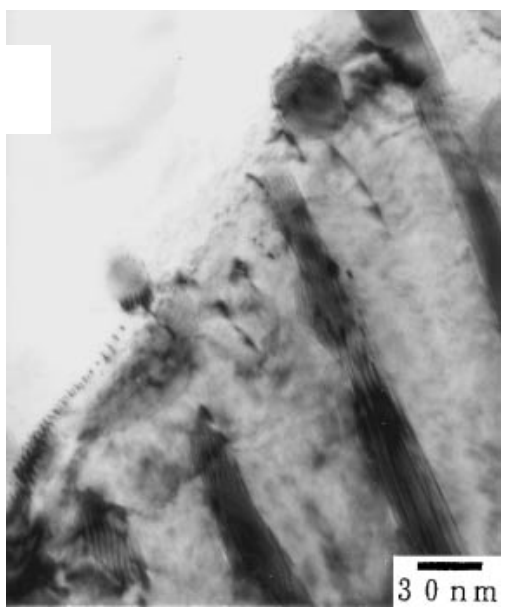

Fig. 5 TEM micrographs of specimens treated under the field gradient of $50 \mathrm{~T} / \mathrm{m}$. (a) Steel D right after the treatment, (b) Steel D annealed at $200^{\circ} \mathrm{C}$, and (c) Steel B annealed at $200^{\circ} \mathrm{C}$.

TEM had been known as one of the most powerful means to probe precipitates in steels, so that observations were carried out with the specimens of Steels B and D. The microstructure of Steel D after the heat treatment under 50 $\mathrm{T} / \mathrm{m}$ is shown in Fig. 5(a). It is a typical pearlite structure, and the dark bars represent cementite layers sandwiched by ferrite layers. When the specimen was subjected to annealing at $200^{\circ} \mathrm{C}$ for $1800 \mathrm{~s}$, small precipitates appeared in the ferrite layers as shown in Fig. 5(b). Such precipitates were also 


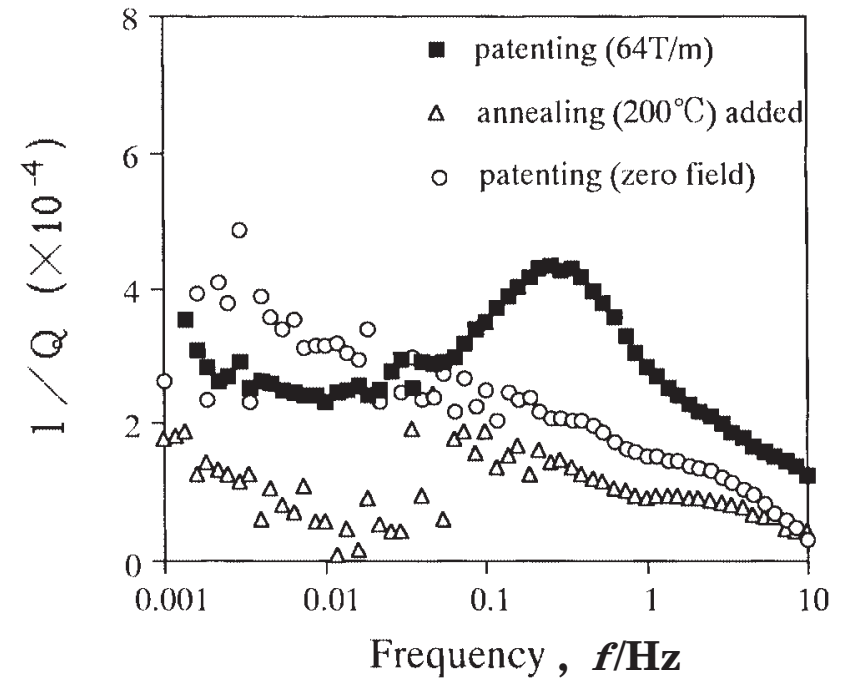

Fig. 6 Internal friction spectra for a specimen made of Steel B. transformed under field gradient $64 \mathrm{~T} / \mathrm{m}, \triangle$ further annealed at $200^{\circ} \mathrm{C}$ and $\bigcirc$ reference specimen transformed in no fields.

observed in the ferrite layers of similarly treated and annealed Steel B, as shown in Fig. 5(c). EDX analysis of the precipitates revealed an enrichment of $\mathrm{Cr}$ atoms for Steel D, and Mn atoms for Steel B. Furthermore, selected electron diffraction analysis has suggested that the precipitates have crystal structures of $\chi$ or $\varepsilon$ carbide. These results lead to a model that extra carbon atoms introduced in ferrite layers under field gradients are responsible for the formation of precipitates and associated age hardening.

The Snoek peak in internal friction has been a very useful measure for carbon atoms dissolved in the ferrite phase of steels. A subresonant torsion pendulum method was adopted to measure the content of interstitial carbon atoms in specimens. This method has an advantage of the Snoek peak measurement without heating a specimen. The results for specimens of Steel B, a steel containing $1 \% \mathrm{Mn}$, are shown in Fig. 6. It is important to note a small and distinct Snoek peak in the curve (ם) for a specimen measured right after the transformation under the field gradient of $64 \mathrm{~T} / \mathrm{m}$. Interstitial carbon content of $13 \mathrm{appm}$ is estimated from the peak height after subtracting the background. It is added here that the general increase of the background toward lower frequencies for the measured curves is ascribed to contributions from dislocation segments in the specimens, and has nothing to do with carbon atoms. On the other hand, the interstitial carbon content was found to be less than $5 \mathrm{appm}$ in a specimen of Steel D with $0.4 \% \mathrm{Cr}$ heat-treated similarly. These values of interstitial carbon content are too small to account for the carbides present after aging at $200^{\circ} \mathrm{C}$. Presumably, most of the extra carbon atoms introduced during the pearlitic transformation under field gradients got combined with $\mathrm{Mn}$ and/or $\mathrm{Cr}$ atoms during quenching to room temperature. Such complexes will not manifest themselves as the Snoek peaks. With this presumption, the hardening after the quenching is interpreted as due to the solution strengthening by such carbon complexes, and the subsequent age hardening to agglomeration of such complexes. Accordingly the negligibly small hardening in Steel F, a binary Fe-C alloy, may be simply explained by the lack of $\mathrm{Mn}$ and/or $\mathrm{Cr}$ atoms in the specimen. The disappearance of the hardening with holding time in the $\mathrm{Pb}$ bath will be explained by the easy diffusion of extra carbons to some sinks such as cementite layers or grain boundaries during such holding.

\subsection{Mechanism of the field gradient effect}

Present results strongly suggest that supersaturated carbon atoms are introduced into pearlitic ferrite layers during the pearlitic transformation in eutectoid carbon steels subjected to external magnetic field gradients. Therefore, the mechanism of the field gradient effect should have a close connection with the transformation itself. According to the Zener-Hillert model, the bulk diffusion of carbon atoms in the austenite phase adjacent to the austenite-pearlitic interface is a rate-determining process in the transformation. ${ }^{10,11)}$ Recently, a ledge mechanism was advocated as an alternative model. ${ }^{12-14)}$ According to this model, the rate-determining process is the interface diffusion of carbon atoms. With these models in mind, plausible arguments are made as follows.

Two mechanisms might be possible for the influence of field gradients on the transformation. One is the magnetic force which selectively acts on the ferromagnetic ferrite phase at the temperature of the transformation. The magnetic force will attract or repel the ferrite phase interface depending on the geometrical relation between the directions of a moving transformation interface and the field gradient vector. Then, one might assume that such force could modify the curvature of the austenite-ferrite interfaces toward concave or convex. A discussion on the relation between the curvature and the carbon content across the interface ${ }^{15)}$ leads to a conjecture that enrichment or depletion of carbon atoms in the ferrite layers will take place. The other mechanism is the possible influence of field gradients on the diffusion coefficient of carbon atoms in austenite or along the interface. If field gradients enhance the mobility of carbon atoms in austenite, more carbon atoms are transported to the interfaces resulting carbon enrichment in the ferrite layers. Here also, a geometrical relation between the moving interface and the field gradient vector will be important since the carbon mobility may be reduced where the sign of the gradient is opposite. Since a polycrystalline pearlite phase is concerned, both mechanisms have a drawback that the enrichment and depletion of carbon atoms could take place with equal probabilities. A remedy for the drawback might be contrived as follows: The enrichment would transiently accumulate extra carbon atoms in the ferrite layers, while the depletion would just reduce the thickness of cementite slightly and the carbon content in the ferrite layers would remain normal.

\section{Conclusion}

It is found that carbon steels of almost eutectoid composition with $\mathrm{Mn}$ and/or Cr additions subjected to the pearlitic transformation become hardened proportional to the magnetic field gradient present during the transformation at $560^{\circ} \mathrm{C}$. The hardness increase amounted to $8 \%$ depending on the composition. An additional requirement for the hardening is that the steels must be kept at the transformation temperature for less than $120 \mathrm{~s}$ before subsequent quenching. The 
hardening is irrelevant to the sign of the gradient and does not show up for homogeneously applied fields. The hardened specimens exhibit further hardening by annealing at $150 \sim 200^{\circ} \mathrm{C}$. TEM observations and internal friction measurements have suggested that supersaturated carbon atoms are introduced into the ferrite layers under the field gradient. Such extra carbon atoms get combined with $\mathrm{Mn}$ and/or $\mathrm{Cr}$ atoms during the quenching to impurity complexes which are responsible for the solution and age hardenings. Plausible mechanisms of the action of field gradients on the introduction of supersaturated carbon atoms have been presented.

\section{Acknowledgements}

Experimental work of this study was partially carried out with Messrs. K. Maruta and Y. Yonehana as a part of the research activities of the Ferrous Super Metal Consortium of Japan under the auspices of the New Energy Development Organization of Japan.

\section{REFERENCES}

1) N. Saunders and A. P. Miodownik: CALPHAD, (Elsevier Science, Oxford, 1998) pp. 253-258.

2) V. D. Sadovskiy, L. Rodigin, L. V. Smirnov, G. M. Filonchik and I. G. Fakidov: Phys. Met. Metallography 12 (1961) 131

3) K. R. Satyanarayan, W. Eliasz and A. P. Miodownik: Acta Metall. 16 (1968) 877.

4) R. Fields and C. D. Graham: Metall. Trans. 7A (1976) 719.

5) M. Enomoto, H. Guo, Y. Tazuke, Y. R. Abe and M. Shimotomai: Metall. Mater. Trans. 32A (2001) 445.

6) M. Shimotomai and K. Maruta: Scripta mater. 42 (2000) 499

7) K. Maruta and M. Shimotomai: Mater. Trans., JIM 41 (2000) 902.

8) M. Shimotomai, K. Maruta, K. Mine and M. Matsui: Acta Mater. 51 (2003) 2921.

9) M. Shimotomai and K. Maruta: Proc. of 3rd Int. Symp. on Electromagnetic Processing of Materials ed. by S. Asai, (The Iron and Steel Institute of Japan, Tokyo, 2000) pp. 600-605.

10) C. Zener: Trans. AIME 167 (1947), 550.

11) M. Hillert: Jernkont. Ann. 141 (1957) 757.

12) S. A. Hackney and G. J. Shiflet: Acta Metall. 35 (1987) 1019.

13) M. J. Whiting and P. Tsakiropoulos: Mater. Sci. Tech. 11 (1995) 977.

14) M. J. Whiting: Scr. Mater. 43 (2000) 969.

15) B. E. Sundquist: Acta Metall. 16 (1968) 1413. 